\title{
Biologia da polinização e sistema reprodutivo de Psychotria barbiflora DC. (Rubiaceae) $^{1}$
}

\author{
Luciana Almeida Gomes Teixeira ${ }^{2,3}$ e Isabel Cristina Machado ${ }^{2}$
}

Recebido em 15/04/2003. Aceito em 11/05/2004

\begin{abstract}
RESUMO - (Biologia da polinização e sistema reprodutivo de Psychotria barbiflora DC. (Rubiaceae)). O estudo foi realizado no período de abril/1999 a setembro/2000, no Parque Estadual Dois Irmãos, Recife (PE) Brasil, um remanescente de floresta Atlântica. Psychotria barbiflora é espécie subarbustiva (0,5-2,0m alt.), com período de floração entre abril e julho e frutificação de junho a setembro. A espécie apresentou heterostilia do tipo distilia, com inflorescências terminais, pendentes, envoltas por brácteas que apresentaram coloração esverdeada durante a floração e tornaram-se arroxeadas na fase de frutificação. As flores abriram por volta das 4h30min e duraram até às $13 \mathrm{~h}$. O volume médio de néctar foi ca. 0,8 e 0,6 $\mu$ l e a concentração de açúcares, aproximadamente 22 e $24 \%$, nas flores longistilas e brevistilas, respectivamente. Os morfos florais apresentaram semelhança em relação ao tamanho da corola, entretanto nas flores brevistilas os grãos de pólen foram maiores e em menor quantidade quando comparado com as flores longistilas. Psychotria barbiflora é melitófila, sendo polinizada por três espécies de abelhas, as quais coletaram néctar e pólen, e por uma espécie de vespa que coletou apenas néctar, em ambos os morfos florais. Baseando-se nos resultados das polinizações manuais e no crescimento dos tubos polínicos, pode-se concluir que esta espécie apresenta auto-incompatibilidade do tipo esporofítica, com formação de frutos apenas nos cruzamentos intermorfos.
\end{abstract}

Palavras-chave: heterostilia, polinização, Psychotria, reprodução, Rubiaceae, tubos polínicos

\begin{abstract}
Pollination biology and breeding system of Psychotria barbiflora DC. (Rubiaceae)). The reproductive biology of Psychotria barbiflora was investigated from April/1999 to September/2000, in the Dois Irmãos State Park, Recife, Pernambuco State, Brazil, an Atlantic Forest remnant. Psychotria barbiflora is a understory species (0.5-2.0m tall), which flowered between April and July and fruiting from June to September. The species presented heterostyly (distyly), and the flowers are arranged in terminal, pendant inflorescences, wrapped in bracts, which are greenish during the flowering period and become purple during the fruiting phase. Anthesis began at about 4:30 a.m. and the flowers last until 1:00 p.m. Recorded nectar volume were c. 0.80 and $0.60 \mu l$ and sugar concentration was approximately 22 and 24\%, respectively, in long and short-styled flowers. The floral morphs were similar in corola size but short-styled flowers had larger, less numerous pollen grains when compared to long-styled ones. Psychotria barbiflora is a mellitophylous species, pollinated by three bee species which were observed collecting nectar and pollen, and also by a wasp species, which collected only nectar, in both floral morphs. Based on the results of hand-pollination tests and observations of pollen-tube growth, it can be concluded that this species has sporophytic self-incompatibility.
\end{abstract}

Key words: heterostyly, pollination, Psychotria, reproduction, Rubiaceae, pollen-tube

\section{Introdução}

A heterostilia é um polimorfismo floral controlado geneticamente, o qual apresenta duas expressões morfológicas, a distilia e a tristilia, caracterizadas, respectivamente, pela ocorrência de dois ou três morfos diferentes quanto ao comprimento de estiletes e filetes (hercogamia recíproca), tamanho e produção de pólen e tamanho das papilas estigmáticas. Além disso, geralmente possui um sistema de incompatibilidade dialélico esporofítico, em que só há formação de frutos nos cruzamentos intermorfos (Vuillemier 1967; Ornduff 1974; Ganders 1979; Barrett \& Richards 1990; Barrett 1992; Kohn \& Barrett 1992).

A família Rubiaceae possui o maior número de espécies heterostílicas dentre as outras 25 famílias de Angiospermas que apresentam este tipo de polimorfismo (Barrett 1992). Bahadur (1968 apud Jung-Mendaçolli \& Melhem 1995) relatou a ocorrência de heterostilia em 416 espécies da família, distribuídas em 31 gêneros, sendo 122 espécies da tribo Psychotrieae. A maioria das espécies de Rubiaceae é

\footnotetext{
Parte da Dissertação de Mestrado da primeira Autora. Bolsista CNPq.

2 Departamento de Botânica, Centro de Ciências Biológicas, Universidade Federal de Pernambuco, CEP 50372-970, Recife, PE, Brasil (imachado@ufpe.br)

3 Autor para correspondência: lagt@ufpe.br; lagt_@hotmail.com
} 
encontrada na região dos trópicos, com hábitos bastante variados, incluindo árvores, arbustos, lianas e poucas espécies herbáceas, epífitas e raramente aquáticas (Robbrecht 1988; Mabberley 1993).

Apesar do grande número de representantes, há poucos trabalhos relacionados com a heterostilia, biologia da polinização e reprodução de representantes de Psychotria, gênero considerado tipicamente distílico (Robbrecht 1988). Dentre estes, pode-se destacar o estudo sobre o sistema reprodutivo de espécies de Rubiaceae, na Costa Rica, incluindo quatro espécies de Psychotria (Bawa \& Beach 1983) e o trabalho sobre a heterostilia e o sistema reprodutivo de P. leiocarpa (Lima 1988). Em seguida, foram desenvolvidos os estudos sobre a variação da distilia em espécies de Psychotria (Hamilton 1990), a análise da morfologia e a distribuição espacial das formas heterostílicas de P. barbiflora em cerrado do Estado de São Paulo (Monteiro et al. 1991), assim como o sistema reprodutivo e a estrutura genética de P. faxlucens (Pérez-Nasser et al. 1993) e a eficiência da polinização de $P$. suerrensis (Stone 1995; 1996). Os trabalhos subseqüentes foram os de Faivre \& McDade (2001), que analisaram os caracteres florais dos indivíduos heterostílicos de Psychotria poeppigraia e $P$. chiapensis, assim como o grau de reciprocidade entre eles e o estudo desenvolvido por Castro \& Oliveira (2002) sobre a polinização de Rudgea jasminoides, por espécies de abelhas e borboletas, e P. birotula, P. mapourioides e $P$. pubigera, apenas por abelhas.

No presente trabalho foram investigados a biologia floral, a polinização e o sistema reprodutivo de Psychotria barbiflora em um fragmento de floresta Atlântica em área urbana de Pernambuco, comparando nossos dados com os descritos para outras espécies do gênero Psychotria.

\section{Material e métodos}

Os estudos de campo foram desenvolvidos no Parque Estadual Dois Irmãos, um fragmento de Mata Atlântica localizado no município de Recife, Estado de

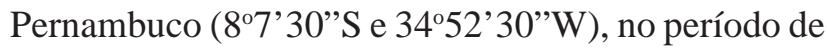
abril/1999 a setembro/2000. O Parque possui extensão aproximada de 370ha, distribuídos em área de relevo levemente ondulado e altitude de 30 a 80m (Machado et al. 1998), fazendo parte da Floresta Estacional Perenifólia Costeira (Andrade-Lima 1961), também denominada Mata Úmida, por Vasconcelos-Sobrinho (1949) ou de Floresta Atlântica, por Rizzini (1979).
Os dados relacionados à biologia floral, como morfologia e cor das flores, horário, duração e seqüência de antese, receptividade do estigma, número de flores abertas por inflorescência e os dados referentes ao néctar (volume e concentração) e ao pólen (morfometria, números de grãos de pólen por antera, por flor, razão pólen/óvulo e viabilidade), foram feitos utilizando-se, para cada análise, dez flores provenientes de 20 indivíduos, dez brevistílicos e dez longistílicos, distribuídos em três trilhas no interior do Parque. Foram feitos desenhos comparativos entre as flores brevistilas e longistilas, com auxílio de câmara clara acoplada a microscópio estereoscópico. A contagem do número de grãos de pólen e óvulos por flor foi feita diretamente sob microscópio estereoscópico, sendo posteriormente calculada a razão pólen/óvulo (Cruden 1977). A viabilidade polínica foi testada em grãos provenientes de duas das cinco anteras de cada flor, pela técnica de coloração do citoplasma por carmim acético 1,2\% (Radford et al. 1974), sendo contados, ao acaso, 100 grãos por lâmina. As medidas de 25 grãos de pólen de cada morfo foram feitas utilizando-se flores frescas de diferentes indivíduos, com auxílio de ocular micrométrica, comparando-se os resultados através de análise de variância.

A concentração de açúcares e o volume do néctar foram medidos em 10 flores de cada morfo, respectivamente, com auxílio de refratômetro de bolso (Atago) e micro-seringas, às $8 \mathrm{~h}$ e $12 \mathrm{~h}$ do dia (Dafni 1992). A receptividade do estigma foi determinada, no campo, por meio da reação com peróxido de hidrogênio utilizando-se cinco flores de cada morfo (Zeisler 1938). Todos os dados referentes a morfometria floral e aos tratamentos de polinizações manuais foram, respectivamente, analisados e comparados pelo teste $U$ (Mann-Whitney/BioEstat 2.0) e pelo teste t (Student/ BioEstat 2.0) (Ayres et al. 2000).

A fenologia da floração e da frutificação foi acompanhada semanalmente no campo entre os meses de abril a setembro, sendo registrados os períodos de emissão de botões, flores, frutos verdes e maduros em 20 indivíduos, dez brevistílicos e dez longistílicos. O padrão de floração da espécie foi descrito de acordo com as classificações de Gentry (1974) e Newstron et al. (1994).

O sistema reprodutivo de P. barbiflora foi estudado através de experimentos de polinizações manuais (autopolinização e polinização cruzada intermorfos) realizados no campo, utilizando-se dez indivíduos de cada morfo (Radford et al. 1974). O 
controle foi feito em dois indivíduos de cada morfo de populações distintas, a partir da marcação de duas inflorescências brevistilas e duas longistilas, totalizando 110 e 150 botões, respectivamente, sendo, posteriormente, contados os frutos e sementes formados, tanto para os tratamentos como para o controle. Os resultados foram analisados estatisticamente pelo teste do Qui-quadrado (X²/BioEstat/2.0) (Ayres et al. 2000).

Para a análise do crescimento dos tubos polínicos, foram feitas polinizações manuais (autopolinizações, polinizações intra e intermorfos) em laboratório, em oito flores brevistilas e oito longistilas, para cada tratamento realizado, provenientes de quatro indivíduos de cada morfo. As flores foram mantidas em caixas de acrílico (gerbox), com meio de ágar-ágar $2 \%$, sendo posteriormente fixadas em FAA 70 nos intervalos de 8, 12, 24 e 48 horas após as polinizações e, em seguida, coradas e analisadas em microscópio de fluorescência (Martin 1959).

Foram realizadas observações, no campo, acerca da freqüência, duração e comportamento dos animais visitantes às flores (recurso floral utilizado e o resultado das visitas, polinização ou pilhagem). O estudo do comportamento dos visitantes foi feito em diferentes horários do dia, complementado através de registros fotográficos. A frequiência de visitas das espécies foi determinada após 35 horas de observação, durante cinco dias (das 6 às 13h), sendo registrado o número de visitas de cada animal por hora. Os visitantes foram coletados com auxílio de rede entomológica e posteriormente montados a seco para identificação. Os espécimes-testemunho encontram-se depositados na coleção do Laboratório de Biologia Floral e Reprodutiva (Departamento de Botânica, UFPE). O material botânico foi coletado, herborizado e depositado como espécime-testemunho no herbário UFP (n. 27.894 e 27.896).

\section{Resultados}

Psychotria barbiflora é espécie subarbustiva, com cerca de 0,5-2,0m alt., distribuída no sub-bosque da mata em três trilhas, principalmente em locais mais úmidos. A espécie é caracterizada por apresentar heterostilia do tipo distílica, com 42 indivíduos de cada morfo, ocorrendo na proporção de 1:1. A floração iniciou entre os meses de abril e maio, estendendo-se até julho, com um pico de produção de flores ocorrendo em meados de junho. A frutificação teve início em junho, estendendo-se até meados de setembro. O tempo de desenvolvimento dos frutos foi de, aproximadamente, três meses. Os frutos, no início do desenvolvimento, apresentaram coloração esverdeada e, quando amadureceram, tornaram-se arroxeados.

As inflorescências são terminais, pendentes, envoltas por brácteas com coloração esverdeada na floração e arroxeada na fase de frutificação. Cada inflorescência produziu entre 50 e 65 botões, em indivíduos brevistílicos, e de 75 a 85 nos longistílicos. As flores são brancas, actinomorfas, pentâmeras e a corola, gamopétala, formando um tubo, com muitos pêlos em toda face interna, apresentando média de $6,5 \mathrm{~mm}$ compr. nas flores brevistilas e $6,8 \mathrm{~mm}$ compr. nas flores longistilas, não havendo diferença significativa quando comparadas estatisticamente (Tab. 1).

$\mathrm{O}$ androceu é formado por cinco estames férteis, com anteras de deiscência longitudinal, filetes epipétalos, apresentando dois níveis de altura no tubo floral, mais baixo nas flores brevistilas e mais alto nas longistilas (Fig. 1). Os grãos de pólen, que são esféricos e inaperturados, apresentaram diferença significativa quando comparados estatisticamente em relação ao diâmetro e a quantidade produzida por cada morfo, sendo maiores e produzidos em maior quantidade nas

Tabela 1. Morfometria floral, diâmetro e número de grãos de pólen por antera e por flor, razão pólen/óvulo (P/O) e viabilidade polínica de Psychotria barbiflora DC. em Recife, PE $(n=10, * n=25) ;{ }^{1 \times 4} U=45, p=0,69 ;{ }^{2 \times 3} U=100, p<0,001$.

\begin{tabular}{|c|c|c|c|}
\hline Caracteres florais & $\begin{array}{l}\text { Flores brevistilas } \\
\overline{\mathrm{x}}(\mathrm{SD})\end{array}$ & $\begin{array}{c}\text { Flores longistilas } \\
\overline{\mathrm{x}}(\mathrm{SD})\end{array}$ & Estatística \\
\hline Comprimento corola (mm) & $6,5(0,28)$ & $6.8(0,63)$ & $\mathrm{U}=34,5, \mathrm{p}=0,21$ \\
\hline Comprimento estilete (mm) & $4,3(0,48)^{1}$ & $7,9(0,74)^{2}$ & $\mathrm{U}=0, \mathrm{p}<0,001$ \\
\hline Altura anteras (mm) & $6,1(0,33)^{3}$ & $4,4(0,73)^{4}$ & $\mathrm{U}=1, \mathrm{p}<0,001$ \\
\hline Diâmetro dos grãos de pólen $(\mu \mathrm{m}) *$ & $63,62(0,52)$ & $47,18(1,30)$ & $\mathrm{U}=24,5, \mathrm{p}<0,001$ \\
\hline Grãos de pólen/antera & $604(62,22)$ & $533(40,05)$ & $\mathrm{U}=65, \mathrm{p}<0,001$ \\
\hline Grãos de pólen/flor & $3.020(196,9)$ & $2.665(161,9)$ & $\mathrm{U}=94, \mathrm{p}<0,001$ \\
\hline $\mathrm{P} / \mathrm{O}$ & $1.510(98,45)$ & $1.333(80,98)$ & $\mathrm{U}=6, \mathrm{p}<0,001$ \\
\hline Viabilidade polínica & $97,9 \%(1,59)$ & $96,7 \%(2,75)$ & $\mathrm{U}=40, \mathrm{p}=0,45$ \\
\hline
\end{tabular}




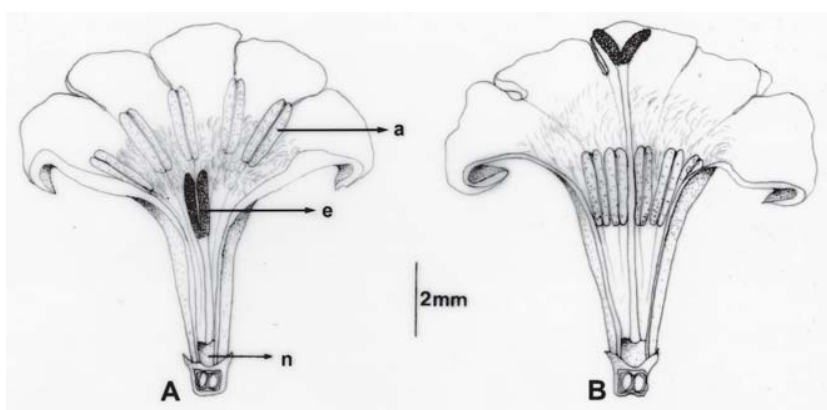

Figura 1. Esquema das flores de Psychotria barbiflora DC. evidenciando as diferenças recíprocas no comprimento do estilete e altura das anteras entre a flor brevistila (A) e a longistila (B) em Recife, PE. a - antera; e - estigma; $\mathrm{n}$ - nectário.

flores brevistilas (Tab. 1). A técnica de acetólise não pôde ser aplicada aos grãos de pólen de $P$. barbiflora devido à fragilidade da exina, ocorrendo seu rompimento e a total deformação dos grãos. A viabilidade polínica das flores brevistilas e longistilas foi alta, em torno de 98 e 97\%, enquanto que a razão pólen-óvulo foi de 1.510 e 1.333 , respectivamente (Tab. 1). As anteras diferiram significativamente em relação ao comprimento apresentando $\bar{x}=2 \mathrm{~mm}(\mathrm{SD}=0)$ para as flores brevistilas e $\bar{x}=1,7 \mathrm{~mm}(\mathrm{SD}=0)$ para as flores longistilas $(\mathrm{U}=0, \mathrm{p}<0,001)$. O gineceu é composto por um estigma bífido, recoberto por papilas estigmáticas, ovário ínfero, bicarpelar, bilocular com dois óvulos, um em cada lóculo (Fig. 1).

Medidas do comprimento dos estiletes e da altura das anteras nas flores brevistilas e longistilas foram feitas, não sendo constatada diferença significativa em relação ao comprimento do estilete das flores brevistilas e a altura das anteras das flores longistilas. Entretanto, a relação entre o comprimento do estilete das flores longistilas e a altura das anteras das flores brevistilas apresentou diferença significativa (Tab. 1).

A antese das flores de P. barbiflora iniciou por volta das $4 \mathrm{~h} 30 \mathrm{~min}$, com a distensão lenta dos lobos da corola. Por volta das $5 \mathrm{~h}$, as flores já estavam completamente abertas com o estigma receptivo e as anteras deiscentes. Diariamente abria de uma a seis flores por inflorescência, tanto nos indivíduos brevistílicos quanto nos longistílicos. O néctar começou a ser produzido, no nectário em forma de disco localizado na base do estilete, logo após a abertura das flores até o início da tarde, por volta das 13h, quando o perianto, o androceu e o estilete da flor escureciam e caiam, ficando apenas o ovário aderido à inflorescência. Foi verificada maior produção de néctar em ambos os morfos na primeira parte da manhã $(\mathrm{U}=19, \mathrm{p}=0,02$; $\mathrm{U}=18, \mathrm{p}=0,02$, flores brevistilas e longistilas, respectivamente) e, próximo às $12 \mathrm{~h}$, houve uma acentuada queda do volume e da concentração (Fig. 2). $\mathrm{O}$ volume de néctar foi semelhante entre os morfos florais às $8 \mathrm{~h}(\mathrm{t}=-1,40, \mathrm{p}=0,17)$ e às $12 \mathrm{~h}(\mathrm{U}=-47$, $\mathrm{p}=0,82)$, sendo verificado o mesmo para a concentração às $8 \mathrm{~h}(\mathrm{t}=0,92, \mathrm{p}=0,36)$ e às $12 \mathrm{~h}(\mathrm{U}=46$, $\mathrm{p}=0,76)$.

Os resultados dos experimentos de polinização manual mostraram a formação de frutos apenas nos cruzamentos intermorfos e o percentual de frutos formados em condições naturais foi de 28 e de $14,6 \%$ nas flores brevistilas e longistilas, respectivamente (Tab. 2). Em relação à análise do crescimento dos tubos polínicos, nos testes de autopolinização manual em flores longistilas, a reação de incompatibilidade ocorreu no segundo terço do estilete, cerca de $12 \mathrm{~h}$ após a polinização (Fig. 3). Para os cruzamentos feitos entre os tipos morfológicos iguais, foi verificado que os tubos polínicos pararam de crescer $12 \mathrm{~h}$ após a polinização, com a formação de "plugs" de calose no início do estilete (Figs. 4 e 6). Quando foi feito o teste de autopolinização manual em flores brevistilas, pôde-se verificar que os tubos polínicos pararam de crescer ainda no estigma, $12 \mathrm{~h}$ após a polinização (Fig. 5). Nos cruzamentos intermorfos, os tubos polínicos chegaram ao ovário 12h após a polinização (Fig. 7) e penetraram no óvulo antes de completar as $24 \mathrm{~h}$ decorrentes da polinização.

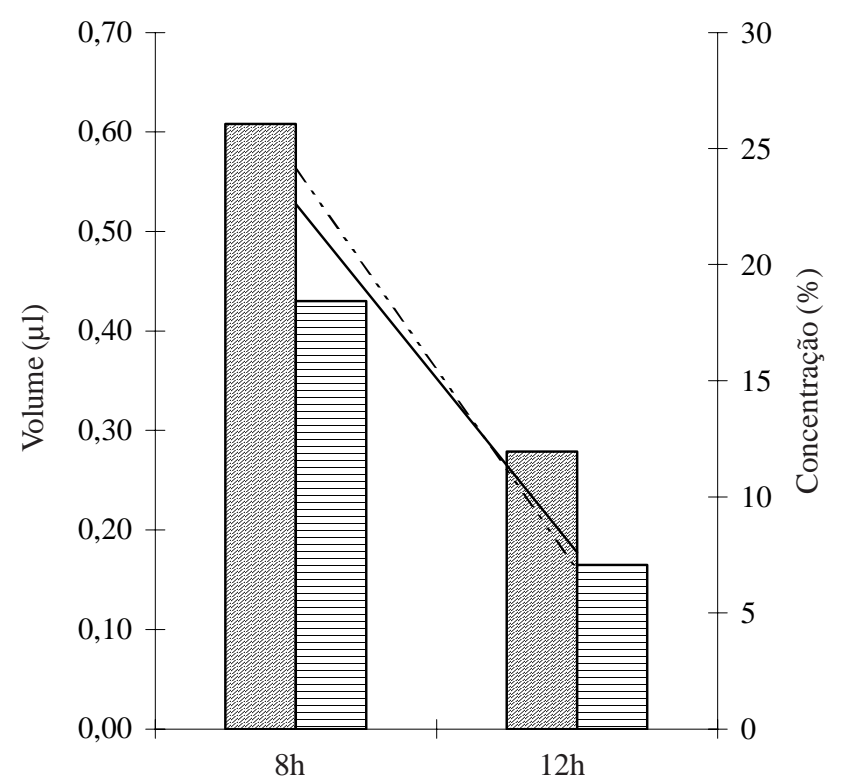

Figura 2. Média do volume e da concentração de açúcares no néctar em flores brevistilas e longistilas $(\mathrm{n}=20)$ de Psychotria barbiflora DC., em Recife, PE. $\square \chi=$ Flores longistilas, $\boxminus=$ Flores brevistilas (volume); - = Flores longistilas, $----=$ Flores brevistilas (concentração). 
Tabela 2. Resultado dos experimentos para verificação do sistema reprodutivo em Psychotria barbiflora DC. em Recife, PE. * Doador de pólen; ** Receptor de pólen.

\begin{tabular}{|c|c|c|c|c|}
\hline Tratamentos & $\begin{array}{l}\text { Flores } \\
\text { (n) }\end{array}$ & $\begin{array}{c}\text { Frutos/Sementes } \\
\text { (n) }\end{array}$ & Sucesso & Estatística \\
\hline $\begin{array}{l}\text { Autopolinização manual } \\
\text { (flores brevistilas) }\end{array}$ & 30 & $0 / 0$ & 0 & - \\
\hline $\begin{array}{l}\text { Autopolinização manual } \\
\text { (flores longistilas) }\end{array}$ & 30 & $0 / 0$ & 0 & - \\
\hline \multicolumn{5}{|l|}{ Polinização cruzada } \\
\hline fl. brevistila* $\times$ fl. longistila**1 & 15 & $7 / 14$ & 46,6 & $X^{2}=5,55, p=0,018$ \\
\hline fl. longistila* $\times$ fl. brevistila**2 & 17 & $12 / 24$ & 70,5 & $\begin{array}{r}\mathrm{X}^{2}=4,78, \mathrm{p}=0,028 \\
1 \times 2 \mathrm{X}^{2}=0,48, \mathrm{p}=0,48\end{array}$ \\
\hline \multicolumn{5}{|l|}{ Controle } \\
\hline fl. brevistila ${ }^{3}$ & 110 & $31 / 62$ & 28 & ${ }^{3 \times 4} \mathrm{X}^{2}=4,6, \mathrm{p}=0,03$ \\
\hline fl. longistila ${ }^{4}$ & 150 & $22 / 44$ & 14,6 & \\
\hline
\end{tabular}

Os visitantes florais de P. barbiflora foram abelhas e vespas, sendo registradas cinco espécies ao todo (Tab. 3). As visitas às flores ocorreram principalmente entre $6 \mathrm{~h}$ e $10 \mathrm{~h} 30 \mathrm{~min}$, período da manhã em que houve maior produção de néctar, e em menor freqüência entre $11 \mathrm{~h}$ e $12 \mathrm{~h} 30 \mathrm{~min}$, período em que as flores estavam com pouco ou quase sem néctar e com as anteras vazias.

As abelhas Trigona fulviventris e $T$. spinipes foram os visitantes mais freqüentes, nos dois morfos florais, iniciando a coleta, tanto de néctar quanto de pólen, por volta das 6 h (Fig. 8 e 9). Durante as visitas às flores brevistilas para coleta de néctar, as abelhas agarravam-se aos lobos da corola e introduziam parte do corpo dentro da flor, ficando os grãos de pólen aderidos nas regiões ventral e dorsal do tórax, enquanto que a cabeça contactava a área estigmática. Entretanto, quando a coleta de néctar era feita em flores longistilas, o local de deposição dos grãos de pólen era, apenas, na região superior da cabeça e o contato com o estigma feito, na maioria das vezes, com a região ventral do tórax e menos freqüentemente com a região dorsal do mesmo. As visitas para coleta de néctar duravam cerca de dois a três segundos e na maioria das vezes todas as flores abertas por inflorescências foram visitadas pelas abelhas. Para a coleta de pólen nas flores brevistilas, as abelhas pousavam nos lobos da corola e, com as pernas anteriores, em movimentos rápidos, faziam a coleta, sendo a deposição do pólen na região ventral do tórax. Em seguida, ainda na flor, rapidamente transferiam os grãos de pólen do tórax, com auxílio das pernas anteriores e medianas, para as pernas posteriores. Nas flores longistilas, as abelhas agarravam-se aos lobos da corola, com as pernas medianas e posteriores e, introduzindo parte do corpo no tubo floral, coletavam os grãos de pólen com as pernas anteriores e transferiam para a região ventral do tórax. Durante a coleta de pólen, as abelhas não entravam em contato com o estigma das flores brevistilas, enquanto que nas flores longistilas, poucas vezes o estigma entrava em contato com a região dorsal do tórax.

As abelhas Ceratinula sp. apresentavam comportamento de pilhagem, uma vez que coletavam néctar por fora do tubo da corola, tanto em flores brevistilas quanto nas longistilas (Fig. 10).

Outra espécie de abelha não identificada foi vista, ocasionalmente, coletando apenas néctar, nos dois morfos florais, por volta das 8h30min. Em vôo rápido, pousava nos lobos reflexos da corola e introduzindo parte do corpo no tubo floral, contactava o estigma das flores brevistilas com a cabeça, local de deposição dos grãos de pólen das flores longistilas. A região dorsal do tórax foi o local de contato com o estigma das flores longistilas e de deposição de pólen das flores brevistilas.

A espécie de vespa da família Scoliidae, muito freqüente, iniciava as visitas para coleta de néctar, nos dois morfos florais, entre $8 \mathrm{~h}$ e $9 \mathrm{~h}$, estendendo-se até, aproximadamente, $12 \mathrm{~h}$. Aproximando-se da flor lentamente, as vespas pousavam nos lobos da corola e, introduzindo a cabeça no tubo floral, coletavam o néctar. Nas flores brevistilas os grãos de pólen ficavam aderidos nas regiões ventral e dorsal do tórax, local de contato com o estigma das flores longistilas, enquanto que a deposição dos grãos das flores longistilas ocorria na região superior da cabeça, sendo este o mesmo 

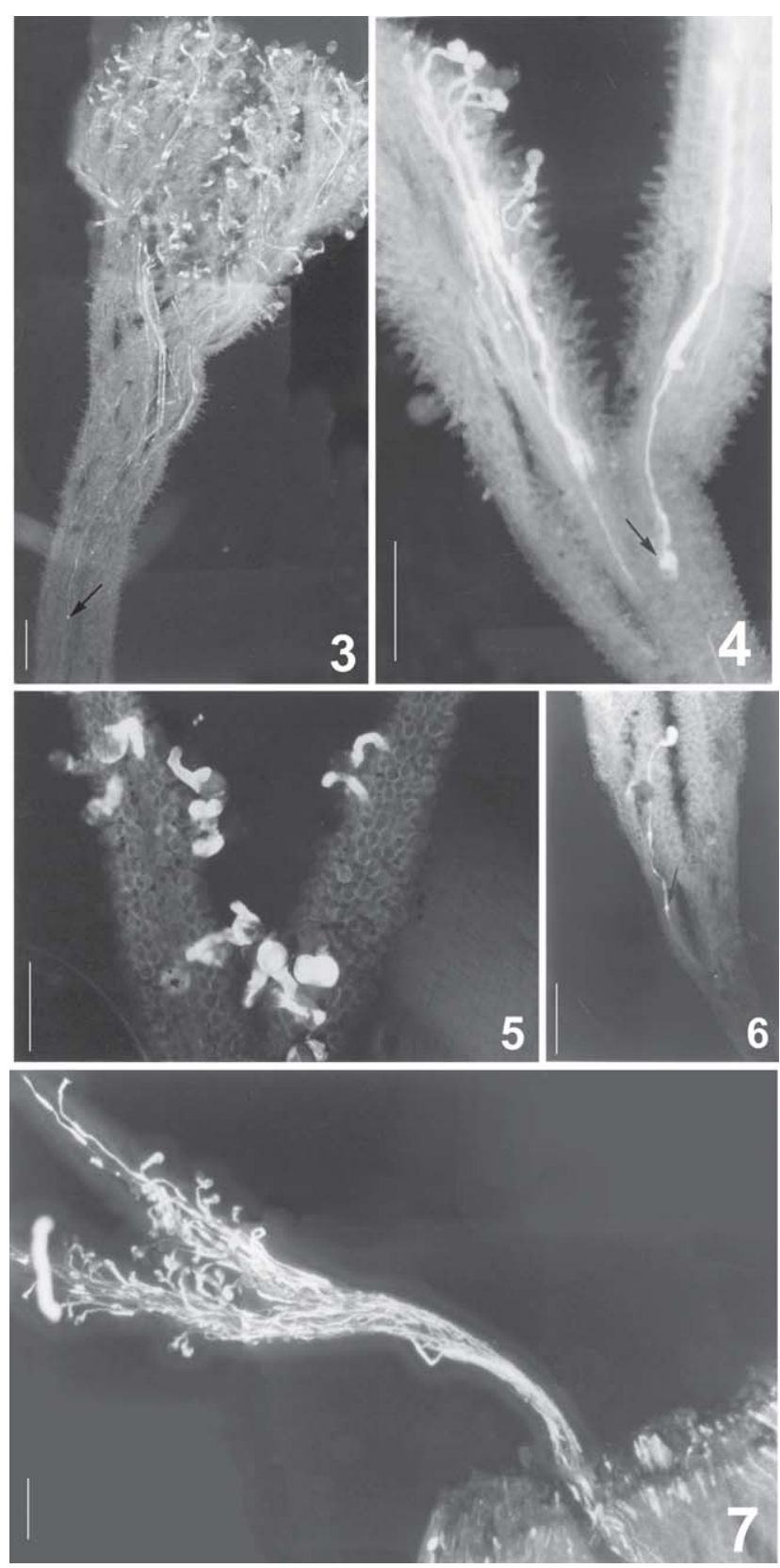

Figuras 3-7. Tubos polínicos, após 12 horas de polinização manual, no gineceu de flores de Psychotria barbiflora DC., em Recife, PE. Estilete de flor longistila após autopolinização mostrando a formação de "plugs” de calose (seta) (3). Interrupção dos tubos polínicos originados de cruzamentos entre flores longistilas evidenciando a reação de incompatibilidade no início do estilete (seta); observar a forma alongada das papilas estigmáticas (4). Detalhe do estigma de flor brevistila após autopolinização, mostrando a interrupção do crescimento dos tubos polínicos (5). Tubos polínicos resultantes de cruzamentos entre flores brevistilas, apresentando reação de incompatibilidade também no início do estilete; observar a forma arredondada das papilas estigmáticas (6). Tubos polínicos de grãos de pólen de flores longistilas penetrando no ovário de flor brevistila, 12 horas após a polinização (7). Escalas $=10 \mu \mathrm{m}$
Tabela 3. Visitantes florais de Psychotria barbiflora DC. e respectivas freqüência, recompensa coletada e resultado da visita em Recife, PE. MF - muito freqüente ( $>6$ visitas/hora), PF - pouco freqüente (< 6 visitas/hora), $\mathrm{P}$ - pólen, $\mathrm{N}$ - néctar, $\mathrm{PO}$ - polinização, PI - pilhagem.

\begin{tabular}{lccc}
\hline Visitantes & Freqüência & $\begin{array}{c}\text { Recurso } \\
\text { coletado }\end{array}$ & $\begin{array}{c}\text { Resultado da } \\
\text { visita }\end{array}$ \\
\hline APIDAE & & & \\
$\quad \begin{array}{l}\text { Trigona fulviventris } \\
\text { Trigona spinipes }\end{array}$ & $\mathrm{MF}$ & $\mathrm{P} / \mathrm{N}$ & $\mathrm{PO}$ \\
ANTHOPHORIDAE & $\mathrm{MF}$ & $\mathrm{P} / \mathrm{N}$ & $\mathrm{PO}$ \\
$\quad$ Ceratinula sp. & $\mathrm{PF}$ & $\mathrm{N}$ & $\mathrm{PI}$ \\
$\quad \begin{array}{l}\text { Anthophoridae sp. 1 } \\
\text { SCOLIIDAE }\end{array}$ & $\mathrm{PF}$ & $\mathrm{N}$ & $\mathrm{PO}$ \\
& $\mathrm{MF}$ & $\mathrm{N}$ & $\mathrm{PO}$ \\
\hline
\end{tabular}

local de contato do estigma das flores brevistilas. As visitas em cada flor duravam, aproximadamente, de três a quatro segundos, e a coleta de néctar era feita em todas as flores abertas por indivíduo.

\section{Discussão}

A heterostilia tem sido relatada para várias espécies de Rubiaceae, incluindo a tribo Psychotrieae com cerca de 122 espécies (Bahadur 1968 apud JungMendaçolli \& Melhem 1995), sendo, principalmente observada no gênero Psychotria (Vuilleumier 1967; Ganders 1979; Bawa \& Beach 1983; Lima 1988; Barrett \& Richards 1990; Hamilton 1990; PérezNasser et al. 1993; Stone 1995, 1996; Castro \& Oliveira 2002). No Parque Estadual de Dois Irmãos, as populações de $P$. barbiflora apresentaram heterostilia do tipo distílica, também registrada para a população de cerrado, em São Paulo (Monteiro et al. 1991). Os indivíduos brevistílicos e longistílicos ocorreram na mesma proporção, indicando isopletia para a espécie, mostrando equilíbrio entre os morfos compatíveis, sendo esta mesma proporção registrada para P. barbiflora, em São Paulo, por Monteiro et al. (1991).

A presença de grãos de pólen com forma esférica inaperturados e dimórficos quanto ao tamanho, sendo maiores nas flores brevistilas, foi também relatada em P. nemorosa, $P$. suterella e P. vellosiana (JungMendaçolli \& Melhem 1995) e em P. leiocarpa (Lima 1988). As deformações por amassamento e rompimento da exina dos grãos de pólen, também foram observados para algumas espécies de Psychotria por Jung-Mendaçolli \& Melhem (1995). Segundo Darwin (1896) e Barrett et al. (1992), a diferença no tamanho 


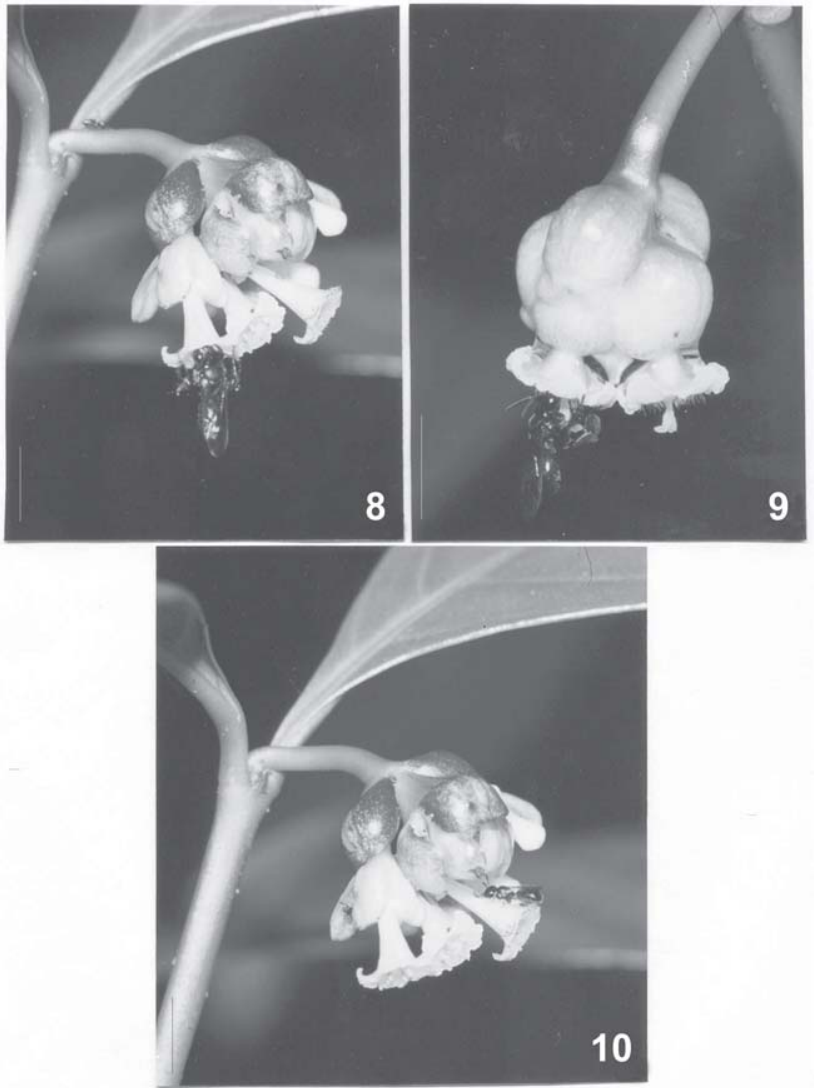

Figuras 8-10. Trigona fulviventris coletando néctar em flor brevistila (8) e longistila (9) e Ceratinula sp. (10) coletando néctar, por fora do tubo da corola, em flor brevistila de Psychotria barbiflora DC. Escalas $=5 \mathrm{~mm}$.

dos grãos de pólen, entre os morfos florais heterostílicos, está relacionada, embora sem evidência, com a quantidade de reserva nutritiva, sendo os grãos de flores brevistilas maiores por possuírem mais reserva para emitir tubos polínicos através dos longos estiletes das flores longistilas.

As características diferenciais entre os morfos florais foram referenciadas de uma forma geral para as espécies heterostílicas, por Vuilleumier (1967), Ganders (1979) e Barrett et al. (1992), os quais associaram as dimensões dimórficas entre os grãos de pólen, superfície e papilas estigmáticas nos morfos florais, com o sucesso nos cruzamentos legítimos, diminuindo ou anulando a possibilidade dos cruzamentos ilegítimos, os quais poderiam permitir combinações deletérias de genes. Em relação à produção dos grãos de pólen em P. barbiflora, foi observado que as flores brevistilas produziram mais, fato igualmente relatado para Palicourea lasiorrachis (Feinsinger \& Busby 1987), divergindo da característica geral das espécies heterostílicas, em que as flores longistilas produzem mais grãos por estes serem menores (Ganders 1979). No entanto, Dulberger (1992) comentou que algumas espécies poderiam apresentar, ou não, variações em relação à produção de grãos de pólen entre os morfos, inclusive serem maiores nas flores brevistilas.

Ainda tratando das características morfológicas das flores distílicas de P. barbiflora, foi observado que o comprimento do estilete das flores longistilas e a altura das anteras das flores brevistilas foram significativamente diferentes, não apresentando reciprocidade. Segundo Darwin (1896) e Hamilton (1990), em muitas espécies heterostílicas o posicionamento recíproco entre os estiletes e estames pode ser exato, embora em muitos casos não seja perfeito. De fato, em P. barbiflora esta relação não foi exata, indicando que há maior dimorfismo no comprimento dos estiletes, entre as formas florais, do que na altura das anteras. Levando em consideração que os filetes são epipétalos, o dimorfismo na altura das anteras pode estar diretamente associado com uma variação no comprimento do tubo floral, o que não ocorreu em $P$. barbiflora. Poucas espécies heterostílicas apresentaram diferenças, entre os morfos florais, em relação ao tamanho da corola (Ganders 1979; Hamilton 1990).

Diversas características das flores de P. barbiflora estão de acordo com a descrição, feita por Endress (1994) para a polinização por abelhas pequenas (espécies do gênero Trigona) e por vespas, tais como flores actinomorfas, pétalas brancas, corola formando um tubo curto e pouca produção de néctar e pólen. Segundo Proctor et al. (1996), as flores polinizadas por vespas são pequenas, apresentando cores opacas e com o néctar de fácil acesso, corroborando as características encontradas aqui para P. barbiflora.

De fato, a concentração de açúcares do néctar, nas flores de ambos os morfos de P. barbiflora, concordou com a amplitude de concentração mencionada na literatura para flores polinizadas por vespas (Baker 1975; Endress 1994). Por sua vez, o baixo volume produzido induziu a repetidas visitas pelos animais em busca de alimento e, conseqüentemente, promoveu a polinização cruzada (Proctor et al. 1996).

O padrão de floração de $P$. barbiflora foi do tipo anual, apresentando apenas um ciclo de floração por ano, com duração intermediária (1-5 meses) e padrão regular, tanto ao nível indivídual, quanto ao nível populacional, de acordo com Newstron et al. (1994) e do tipo steady-state (sensu Gentry 1974), com poucas flores abertas por dia, o que pode ter promovido maior 
deslocamento dos polinizadores entre os indivíduos, e entre os morfos florais, aumentando, dessa forma, a possibilidade de xenogamia.

Os resultados dos experimentos de polinização em campo mostraram que houve maior formação de frutos nas polinizações cruzadas manuais intermorfos do que no controle. Este fato pode estar relacionado com a ocorrência de poucos indivíduos de abelhas e vespas visitando as flores, principalmente no período de pico na floração, apesar de terem sido de certa forma eficientes, pois todos os frutos formados no tratamento de controle apresentaram duas sementes. Deve-se considerar que os indivíduos de formas florais semelhantes e diferentes de P. barbiflora estavam localizados próximos entre si, nas trilhas em que o estudo foi desenvolvido, não sendo a distância, entre os morfos, fator limitante para abelhas pequenas como Trigona, no transporte da carga polínica. Em compensação, os resultados do número de frutos formados nas polinizações cruzadas mostraram bom percentual nos dois morfos, indicando a possível capacidade máxima da espécie na formação de frutos.

A formação de frutos em flores não manipuladas (controle) foi diferente entre os morfos florais, tendo maior sucesso nas flores brevistilas. O fluxo assimétrico de pólen entre os morfos é considerado comum nas espécies heterostílicas, e alguns autores chegaram a conclusão de que o estigma das flores longistilas recebem mais grãos de pólen ilegítimos, por estarem mais expostos do que os estigmas das flores brevistilas (Ganders 1979; Dulberger 1992). Os visitantes de $P$. barbiflora podem ter promovido a geitonogamia nas flores, principalmente nas longistilas, com acúmulo de grãos de pólen incompatíveis dificultando ou impossibilitando a germinação dos grãos de pólen compatíveis e, conseqüentemente, diminuindo a formação de frutos, fato esse, chamado de "clogging" por Lloyd \& Yates (1982) e Webb \& Lloyd (1986). Outro fator que pode ter influenciado essa baixa formação de frutos é a possibilidade de, durante algumas visitas às flores longistilas, não ter ocorrido o contato do corpo do animal com a superfície estigmática, fato que foi observado e questionado por Stone (1995) para P. suerrensis. Monteiro et al. (1991) observaram que as plantas com flores longistilas formaram mais frutos do que as brevistilas, sugerindo uma possível função feminina às flores longistilas para $P$. barbiflora nas populações observadas por eles no cerrado. Entretanto, neste trabalho, foi observada maior formação de fruto nas flores brevistilas.
O sistema de auto-incompatibilidade heteromórfico envolve mecanismo esporofítico em que a reação do pólen é determinada pelo genótipo do esporófito parental, podendo esta reação ser observada em locais diferentes nos dois morfos (Gibbs 1986; Dulberger 1992). Em P. barbiflora, nas autopolinizações de flores brevistilas, os tubos polínicos pararam de crescer na superfície estigmática e este resultado foi, também, relatado para nove de 10 espécies de Rubiaceae estudadas por Bawa \& Beach (1983), assim como para Manettia luteo-rubra (Passos \& Sazima 1995). Segundo Gibbs (1990), as espécies com autoincompatibilidade heteromórfica apresentam rejeição no estigma, principalmente em autopolinizações de flores brevistilas. Entretanto, na autopolinização de flores longistilas, a inibição dos tubos polínicos ocorre na região mediana do estilete, assim como observado em $P$. chiapensis e $P$. officinalis por Bawa \& Beach (1983). Nos cruzamentos intramorfos de flores brevistilas e longistilas, o local de inibição dos tubos polínicos foi o começo do estilete, logo abaixo do estigma. De acordo com Bawa \& Beach (1983), para as 10 espécies de Rubiaceae estudadas, o local de inibição dos tubos polínicos nos cruzamentos intramorfos de flores brevistilas foi a superfície estigmática, enquanto que houve variação, do estigma até a base do estilete, no local de inibição dos tubos polínicos das flores longistilas. Estes resultados em P. barbiflora indicaram que a incompatibilidade foi mais fortemente expressada nas flores brevistilas, principalmente pelo fato de, nas autopolinizações, os tubos polínicos nem terem sido emitidos, diferentemente das flores longistilas, em que a reação ocorreu, apenas, mais tardiamente.

De uma forma geral, as espécies de Rubiaceae apresentam grande variedade de animais visitantes às suas flores e, apesar de existirem poucas informações a este respeito, em algumas espécies de Psychotria há registros de abelhas e vespas. Abelhas do gênero Trigona foram referenciadas como os únicos polinizadores de P. marginata (Hamilton 1990). Em $P$. suerrensis, foram observadas sete espécies de abelhas, dentre elas Trigona fulviventris, e algumas vespas, mas estas não foram os polinizadores mais eficientes, sendo considerados assim, espécies de Euglossa e Exaerete (Stone 1996). De fato, abelhas do gênero Trigona foram os principais polinizadores de $P$. barbiflora, juntamente com uma espécie de vespa da família Scoliidae, as quais demonstraram serem aptas para o transporte de pólen entre os morfos florais, principalmente por apresentarem deposição dos grãos de pólen no corpo, correlacionados com a posição 
dos estigmas de flores brevistilas e longistilas. Entretanto, alguns autores (Percival 1965; Faegri \& Pijl 1979; Proctor et al. 1996), não consideraram as vespas como grandes polinizadores, principalmente por apresentarem aparelho bucal primitivo, com a língua achatada, e por consumir néctar apenas como suplemento alimentar.

As abelhas e vespas foram observadas visitando as flores de $P$. barbiflora em maior frequência, principalmente na primeira parte da manhã, até aproximadamente $10 \mathrm{~h}$, fato que pode estar relacionado com a maior produção de néctar nesse período. Além disso, a disponibilidade dos grãos de pólen foi maior, também, na primeira parte da manhã, estando as anteras quase totalmente vazias após $11 \mathrm{~h}$. Entretanto, foram observados poucos indivíduos, tanto das abelhas do gênero Trigona como da espécie de Scoliidae, visitando as flores, principalmente nas áreas onde os indivíduos de P. barbiflora apresentaram distribuição mais agregada, com maior quantidade de flores abertas, o que teoricamente aumentaria o número de visitantes em busca de recursos como o néctar e o pólen.

A razão pólen-óvulo para as flores brevistilas e longistilas de P. barbiflora correspondeu ao tipo de sistema reprodutivo envolvendo a xenogamia facultativa, segundo classificação de Cruden (1977). Entretanto, outros métodos, como os testes de polinizações manuais e a análise do crescimento do tubo polínico, utilizados para avaliar o sistema reprodutivo em $P$. barbiflora, mostraram que a espécie apresentou xenogamia obrigatória, dependendo, dessa forma, da eficiência dos polinizadores para sua manutenção.

\section{Agradecimentos}

À Daniela Zappi, pela identificação de Psychotria barbiflora; à Ariadna Valentina Lopes, Paulo Eugênio Oliveira, Clemens Schlindwein e dois assessores anônimos, pelas sugestões ao manuscrito; à Isa Regina Leite, Ana Virgínia Leite e Cleci Neves, pela ajuda no campo e no laboratório; à Marina Machado Adeodato, pela confecção do abstract e à Priscila Martini, pela revisão; a André Santos e Tarcila Nadia, pela ajuda nos cálculos estatísticos; à Ana Emília e Reginaldo, pela ajuda na utilização do microscópio de fluorescência; a Celso Martins, pela identificação da vespa; à Direção do Parque Dois Irmãos, pela autorização para a realização dos trabalhos de campo; ao CNPq, pelo auxílio financeiro.

\section{Referências bibliográficas}

Andrade-Lima, D. 1961. Tipos de florestas de Pernambuco. Anais da Associação dos Geógrafos Brasileiros 12: 69-85.

Ayres, M.; Ayres, Jr. M.; Ayres, D.L. \& Santos, A.S. 2000. BioEstat 2.0: Aplicações estatísticas nas áreas de ciências biológicas e médicas. Belém, Sociedade Civil Manirauá e CNPq.

Baker, H.G. 1975. Sugar concentrations in nectars from hummingbird flowers. Biotropica 7: 37-41.

Barrett, S.C.H. 1992. Heterostylous genetic polymorphisms: model systems for evolutionary analysis. Pp. 1-24. In: S.C.H. Barrett (ed.). Evolution and function of heterostyly. Monographs on Theorical and Applied Genetics. Springer-Verlag, Berlin.

Barrett, S.C.H. \& Richards, J. H. 1990. Heterostyly in tropical plants. Memoirs of the New York Botanical Garden 55: 35-61.

Bawa, K.S. \& Beach, J.H. 1983. Self-incompatibility systems in the Rubiaceae of a tropical lowland wet forest. American Journal of Botany 70: 1281-1288.

Castro, C.C. \& Oliveira, P.E.A.M. 2002. Pollination Biology of distylous Rubiaceae in the Atlantic Rain Forest, SE Brazil. Plant Biology 4: 640-646

Cruden, R.W. 1977. Pollen-ovule ratios: a conservative indicator of breeding systems in flowering plants. Evolution 31: 32-46.

Dafni, A. 1992. Pollination ecology - A practical approach. Oxford University Press.

Darwin, C.R. 1896. The different forms of flowers on plants of the same species. D. Aplleton and Company. New York.

Dulberger, R. 1992. Floral polymorphisms and their functional significance in the heterostylous syndrome. Pp. 41-84. In: S.C.H. Barrett (ed.). Evolution and function of heterostyly. Monographs on Theoretical and Applied Genetics. Springer-Verlag, Berlin.

Endress, P.K. 1994. Diversity and evolutionary biology of tropical flowers. Cambridge University Press, Cambridge.

Faegri, K. \& Pijl, L. 1979. The principles of pollination ecology. London, Pergamon Press.

Faivre, A.E. \& McDade, L.A. 2001. Population-level variation in the expression of heterostyly in three species of Rubiaceae: does reciprocal placement of anthers and stigmas characterize heterostyly? American Journal of Botany 88: 841-853.

Feinsinger, P. \& Busby, W.H. 1987. Pollen carryover: experimental comparisons between morphs of Palicourea lasiorrachis (Rubiaceae), a distylous, birdpollinated, tropical treelet. Oecologia 73: 231-235.

Ganders, F.R. 1979. The biology of heterostyly. New Zealand Journal of Botany 17: 607-635.

Gentry, A.H. 1974. Flowering phenology and diversity in tropical Bignoniaceae. Biotropica 6: 64-68.

Gibbs, P. 1986. Do homomorphic and heteromorphic selfincompatibility systems have the same sporophytic mechanism? Plant Systematics and Evolution 154: 285-323. 
Gibbs, P. 1990. Self-incompatibility in flowering plants: a neotropical perspective. Revista brasileira de Botânica 13: $125-136$

Hamilton, C.W. 1990. Variations on a distylous theme in Mesoamerican Psychotria subgenus Psychotria (Rubiaceae). Memoirs of the New York Botanical Garden 55: 62-75.

Jung-Mendaçolli, S. \& Melhem, T. 1995. Grãos de pólen de espécies heterostílicas de Rubiaceae. Revista Brasileira de Botânica 18: 61-93.

Kohn, J.R. \& Barrett, S.C. 1992. Experimental studies on the functional significance of heterostyly. Evolution 46: 43-55.

Lima, H.A. 1988. Heterostilia em Psychotria leiocarpa Cham. \& Schl. (Rubiaceae). Boletim do Museu Nacional 76: $1-16$.

Lloyd, D.G. \& Yates, C.J. 1982. Intrasexual selection and segregation of pollen and stigmas in hermaphrodite plants, exemplified in Wahlenbergia albomarginata (Campanulaceae). Evolution 36: 909-913.

Mabberley, D.J. 1993. The Plant-Book. A portable dictionary of the higher plants. Cambridge, Cambridge University Press.

Machado, I.C.; Lopes, A.V. \& Pôrto, K.C. 1998. Reserva Ecológica de Dois Irmãos: Estudos em um remanescente de Mata Atlântica em área urbana. SECTMA (Secretaria de Ciência, Tecnologia e Meio Ambiente) Recife, Editora Universitária, UFPE.

Martin, F.W. 1959. Staining and observing pollen tubes in the style by means of fluorescence. Stain Technology 34: 125-128.

Monteiro, R.; Nakajima, J.N.; Ribeiro, J.L.S. \& Toledo, J.C. 1991. Morfologia e distribuição espacial das formas heterostílicas de Psychotria barbiflora DC. (Rubiaceae). Naturalia 16: 137-146.

Newstron, L.E.; Frankie, G.W. \& Baker, H.G. 1994. A new classification for plant phenology based on flowering patterns in Lowland Tropical Rain Forest Trees at La Selva, Costa Rica. Biotropica 26: 141-159.
Ornduff, R. 1974. Heterostyly in South African flowering plants: A conspectus. Journal of South African Botany 40: $169-187$.

Passos, L. \& Sazima, M. 1995. Reproductive biology of the distylous Manettia luteo-rubra (Rubiaceae). Botanica Acta 108: 309-313.

Percival, M. 1965. Floral Biology. Pergamon Press. London.

Pérez-Nasser, N.; Eguiarte, L.E. \& Piñero, D. 1993. Mating system and genetic structure of the distylous tropical tree Psychotria faxlucens (Rubiaceae). American Journal of Botany 80: 45-52.

Proctor, M.; Yeo, P. \& Lack, A. 1996. The natural history of pollination. Harper Collins Publishers, London.

Radford, A.E.; Dickinson, W.C.; Massey, J.R. \& Bell, C.R. 1974. Vascular plant systematics. New York, Harper \& Row Publishers.

Rizzini, C.T. 1979. Tratado de fitogeografia do Brasil, 2. Aspectos sociológicos e florísticos. São Paulo, Ed. da Universidade de São Paulo.

Robbrecht, E. 1988. Tropical woody Rubiaceae. Opera Botanica Belgica 1: 1-271.

Stone, J.L. 1995. Pollen donation patterns in a tropical distylous shrub (Psychotria suerrensis; Rubiaceae). American Journal of Botany 82: 1390-1398.

Stone, J.L. 1996. Components of pollination effectiveness in Psychotria suerrensis: a tropical distylous shrub. Oecologia 107: 504-512.

Vasconcelos-Sobrinho, J. 1949. As regiões naturais de Pernambuco. Arquivos do Instituto de Pesquisas Agronômicas 3: 25-33.

Vuilleumier, B.S. 1967. The origin and evolutionary development of heterostyly in the angiosperms. Evolution 21: 210-226.

Webb, C.J. \& Lloyd, D.G. 1986. The avoidance of interference between the presentation of pollen and stigmas in angiosperms. II. Herkogamy. New Zealand Journal of Botany 24: 163-178.

Zeisler, M. 1938. Über die Abgrenzung der eigentlichen Narbenfläche mit Hilfe von Reaktionen. Beiheft Botanisches Zentralblatt 58: 308-318. 